\title{
Effect of Surface Treatment With Er:YAG and CO2 Lasers on Shear Bond Strength of Polyether Ether Ketone to Composite Resin Veneers
}

\author{
Yousef Jahandideh, Mehran Falahchai, Hossein Pourkhalili* \\ Dental Sciences Research Center, Department of Prosthodontics, School of Dentistry, Guilan University of Medical \\ Sciences, Rasht, Iran
}

\section{*Correspondence to Hossein Pourkhalili, Assistan Professor, Dental Sciences Research Center, Department of Prosthodontics, School of Dentistry, Guilan University of Medical Sciences, Rasht, Iran. Tel: +98-9132078185 Email: hpkhalili@gmail.com}

Published online March 15, 2020

\begin{abstract}
Introduction: Polyether ether ketone (PEEK) has low surface energy and high resistance to chemical surface treatments. Therefore, different surface treatments such as laser conditioning should be investigated. There is a gap of information regarding the efficacy of laser irradiation in the surface treatment of PEEK, and the efficacy of several laser types needs to be evaluated for this purpose. This study aimed to assess the effect of surface treatment with erbium-doped yttrium aluminum garnet (Er:YAG) and carbon dioxide (CO2) lasers on shear bond strength (SBS) of PEEK to composite resin veneers.

Methods: In this experimental study, 60 rectangular-shaped PEEK samples $(7 \times 7 \times 2 \mathrm{~mm})$ were used. The samples were mounted in auto-polymerizing acrylic resin in such a way that only one surface measuring $7 \times 7 \mathrm{~mm}$ remained exposed. The samples were then randomly divided into 3 groups $(n=20)$ of control, Er:YAG laser surface treatment (Power $=1.5 \mathrm{~W}$, energy density $=119.42 \mathrm{~J} / \mathrm{cm}^{2}$, irradiation time $=20 \mathrm{~s}$ ) and CO2 laser surface treatment (Power $=4 \mathrm{~W}$, energy density $=159.22 \mathrm{~J} / \mathrm{cm}^{2}$, irradiation time $=50 \mathrm{~s}$ ). The bonding agent and PEEK opaque were applied on the surface of samples and they were veneered with a composite resin using a hollow plastic cylinder with an internal diameter of $4 \mathrm{~mm}$. The SBS was then measured and the data were analyzed using one-way ANOVA, Tukey HSD test and Dunnett's test at 0.05 level of significance.

Results: The SBS of the 3 groups was significantly different $(P<0.001)$. The Tukey HSD test revealed that the Er:YAG laser had higher SBS than the CO2 laser group $(P<0.001)$. The Dunnett's test showed that both Er:YAG and CO2 laser groups yielded higher SBS than the control group $(P<0.001)$.

Conclusion: The Er:YAG and CO2 laser treatments can increase the SBS of PEEK to composite resin veneers, although the Er:YAG laser seems to be more effective for this purpose.

Keywords: Er-YAG Lasers; CO2 Lasers; Polyether ether ketone; Surface treatment.
\end{abstract}

\begin{abstract}
Introduction
Composite materials fabricated by the computer-aided design/computer-aided manufacturing techniques have shown promising results when used for dental restorations. However, due to some shortcomings, new generations of dental composites have been introduced to the market, including polyaryletherketone, polyether ether ketone (PEEK), polyetherketoneketone, and PEEK/ polyetherketoneketone reinforced with mineral fillers, which have optimal wear properties. ${ }^{1}$ PEEK is a toothcolor synthetic polymer from the polyaryletherketone family and is a new type of high-temperature thermoplastic polymer with an aromatic molecular chain and functional ketone and ether groups attached to each other. ${ }^{2}$ Its advantages include natural appearance resembling that of natural teeth (compared to metal), an easy shaping ability by dental burs, lower cost than gold,
\end{abstract}

lower weight compared to ceramics and titanium, easy use, optimal biocompatibility, low plaque accumulation, and elasticity properties similar to those of bone, enamel and dentin, which make it suitable for use as a restorative material. ${ }^{3}$ PEEK also has favorable dimensional stability at high temperatures (melting temperature $>300^{\circ} \mathrm{C}$ ), high chemical and mechanical resistance to wear and high tensile strength, fatigue resistance, and flexural strength. ${ }^{4}$ Thus, it has several dental applications in dental implants, implant abutments, removable dentures, and fixed partial dentures. ${ }^{5}$ However, PEEK has such a shortcoming as its optical properties including low translucency and gray color, limiting its application for monolithic restorations. Thus, a layer of composite resin should be applied over it, which may compromise achieving a strong bond between the composite resin and PEEK. PEEK has low surface energy and high resistance to chemical surface treatments 
because the aromatic chemical structure of ketone and other constituents of PEEK create an inert surface with suboptimal bonding capabilities. ${ }^{6-8}$ Therefore, since a durable bond is imperative for the long-term service and durability of restorations, several methods such as chemical adhesion, mechanical retention or a combination of both have been suggested to enhance the bond. ${ }^{9}$ These strategies are commonly used for metal and ceramic veneers. Thus, they may be applicable to PEEK as well. ${ }^{8,10}$ Previous studies have indicated that surface treatment is imperative to achieve a strong bond between PEEK and composite resin.,9-14 The commonly used surface treatments include air abrasion, silica coating, acid etching and plasma treatment to enhance surface wetting and bond strength. ${ }^{15}$ The results regarding the efficacy of these techniques have been controversial and inconclusive. However, the majority of studies have shown that surface treatment with $98 \%$ sulfuric acid yields higher shear bond strength (SBS) than other methods. ${ }^{2,10,16-19}$ However, due to its highly corrosive nature, sulfuric acid with such a high concentration cannot be used in the clinical setting since it can cause serious injury when it is in contact with the mucosa. ${ }^{17}$

Energetic treatments such as plasma or corona discharge on polymers have shown promising results. ${ }^{20-22}$ However, laser treatment has some advantages; it can be applied to a specific area, offers different treatments, and leads to more accurate results with little surface damage. Laser treatment has been used in the past to functionalize the surfaces of several low-energy polymers to enhance their usability in multiple applications. ${ }^{22,23}$ As PEEK is a thermoplastic polymer, it may be affected by laser treatment. ${ }^{24}$ Therefore, It seems that laser irradiation may be a promising alternative to improve the bond strength without changing the main bulk features of the material.

There are several types of lasers which can be utilized, such as Erbium-doped yttrium aluminum garnet (Er:YAG) and carbon dioxide (CO2). A study by Zhang et al who examined the effect of laser treatment on flamesprayed PEEK coating showed that the CO2 laser beam is better melted than the Nd:YAG laser. ${ }^{25}$ Moreover, in studies on the densification of polymer coatings, it was found that the $\mathrm{CO} 2$ laser was easily absorbed by polymers. ${ }^{25-27}$ On the other hand, the majority of studies on the surface treatment of PEEK with lasers have focused on the bond strength of PEEK to resin cement and have reported controversial results. ${ }^{15,17,28} \mathrm{~A}$ search of the literature by the authors revealed one previous study on the effect of Er:YAG laser treatment on bond strength of composite resin veneers to PEEK. They observed that a combination of airborne-particle abrasion or silica coating with Er:YAG laser irradiation provided a durable bond while the Er:YAG laser beam alone did not enhance the bond strength. ${ }^{29}$ Therefore, surface treatment seems imperative to enable a bond between PEEK and composite resin veneers. On the other hand, alternative approaches should be studied as well. Moreover, there is a gap of information regarding the efficacy of laser irradiation in the surface treatment of PEEK, and the efficacy of several laser types needs to be evaluated for this purpose. This study aimed to assess the effect of surface treatment of PEEK with Er:YAG and CO2 lasers on the SBS of PEEK to composite resin veneers. The null hypothesis was that the SBS of PEEK to composite resin veneers would not be affected by laser surface treatment.

\section{Materials and Methods}

In this in vitro, experimental study, 60 rectangular samples of PEEK (Bio-HPP, Bredent, Germany) measuring 7 $\times 7 \times 2 \mathrm{~mm}$ were fabricated by a cutting machine. The samples were mounted in auto-polymerizing acrylic resin (Acrosoft SL, Marlic, Iran) in such a way that only one surface measuring $7 \times 7 \mathrm{~mm}$ remained exposed. The surface of samples was polished using 400-1000-grit silicon carbide abrasive papers for 10 seconds with finger pressure. All samples were cleaned in an ultrasonic bath containing deionized water for 10 minutes. The samples were then randomly divided into 3 groups $(n=20)$ as follows:

1. Control group: No surface treatment

2. CO2 group: The surface of samples was irradiated with the CO2 laser (DS 10UD, Daeshin, Korea) with $4 \mathrm{~W}$ power, the energy density of $159.22 \mathrm{~J} / \mathrm{cm}^{2}$, a $10600 \mathrm{~nm}$ wavelength and $50 \mathrm{~s}$ irradiation time in a continuous mode. The laser was irradiated using a noncontact handpiece (spot size: $4 \mathrm{~mm}$ ) with Air cooling. ${ }^{30}$

3. Er:YAG group: The surface of samples was irradiated with the Er:YAG laser (2940 D Plus, DEKA, Italy) with a $2940 \mathrm{~nm}$ wavelength, $150 \mathrm{~mJ}$ energy, $20 \mathrm{~s}$ irradiation time, $1.5 \mathrm{~W}$ output power and $119.42 \mathrm{~J} /$ $\mathrm{cm}^{2}$ energy density in a pulse mode $(10 \mathrm{~Hz})$ with $700 \mu$ s pulse duration at a $10 \mathrm{~mm}$ distance using a 4 $\mathrm{mm}$ diameter titanium articulated arm transmission system (spot size: $4 \mathrm{~mm}$ ) with a sweeping motion. The surface was cooled with water spray at a $5 \mathrm{~mL} /$ min rate during laser irradiation. ${ }^{31}$

After surface treatment, a thin layer of adhesive (VisioLink, Bredent, Germany) was applied on the surface of the samples with one movement of a micro-brush and immediately light-cured for 90 seconds using dental laboratory polymerizer (Labolight LV III, GC, Japan). Next, a thin layer of resin opaquer (Crea.Lign Opaquer A2, Bredent $\mathrm{GmbH}$, Senden, Germany) was applied on the entire surface of the samples and light-cured for 180 seconds. An empty hollow plastic cylinder with an internal diameter of $4 \mathrm{~mm}$ and a height of $1.5 \mathrm{~mm}$ was placed on the surface of the samples and one layer of the veneering composite resin (Crea.lign paste A2, Bredent $\mathrm{GmbH}$, Senden, Germany) with $1.5 \mathrm{~mm}$ thickness was applied on the samples and light-cured for 180 seconds according to the manufacturer's instructions. The samples 
were stored in distilled water at $37^{\circ} \mathrm{C}$ for 24 hours. The SBS of specimens was measured using a universal testing machine (STM-20, Santam, Iran) at a crosshead speed of $1 \mathrm{~mm} / \mathrm{min}$.

The collected data were analyzed using SPSS version 21 . The normal distribution of data was evaluated using the Shapiro-Wilk test. One-way ANOVA was used to compare the means of the SBS of the 3 groups. The Tukey HSD test was used for the pairwise comparison of the Er:YAG laser and CO2 laser groups while the Dunnett's test was applied to compare these 2 groups with the control group $(\alpha=0.05)$

\section{Results}

The Kolmogorov-Smirnov test and the Shapiro-Wilk test showed that the SBS data were normally distributed. Table 1 shows the mean and standard deviation of the SBS of the groups.

One-way ANOVA revealed a significant difference in the SBS of the 3 groups $(P<0.001)$. The Tukey HSD test compared the SBS of the Er:YAG laser and CO2 laser groups and showed that the Er:YAG laser group had $3.86 \pm 0.58 \mathrm{MPa}$ higher SBS than the CO2 laser group $(P<0.001)$. The Dunnett's test compared the SBS of the Er:YAG laser and CO2 laser groups with that of the control group and showed that both lasers yielded higher SBS than the control group $(6.76 \pm 0.58$ and $2.9 \pm 0.58$ $\mathrm{MPa}$ respectively); these differences were statistically significant $(P<0.001)$.

\section{Discussion}

This study aimed to assess the effect of Er:YAG and CO2 lasers on the SBS of PEEK to composite resin veneers. The results showed that both laser types yielded a higher bond strength than the control group in such a way that the Er:YAG laser yielded the highest and the control group yielded the lowest SBS value. Thus, the null hypothesis regarding no significant effect of laser irradiation on the SBS of PEEK to composite resin veneers was rejected.

In this study, adhesive resins and opaque composites were applied prior to the surface treatment and the application of the veneering. Previous studies have shown the optimal efficacy of adhesive resins in creating a durable bond between PEEK and composite resin veneers. ${ }^{9,11,12,18}$ Also, the majority of manufacturers have recommended different adhesive systems for this purpose. ${ }^{8}$ Thus, in this study, chemical bonding was achieved by the application of adhesive resins and opaque composites. A recent study revealed that Visio-Link yielded the strongest bond of resins to PEEK. Visio-Link contains pentaerythritol triacrylate in the form of a solution, methyl methacrylate monomers, and dimethacrylates. ${ }^{12}$

The SBS, pull-out, tensile and microtensile tests have been suggested to measure the bond strength. It is important to apply the stress to the bonding interface irrespective of the type of test used. Some studies performed
Table 1. The Mean SBS (MPa) of the Samples Subjected to Different Surface Treatments

\begin{tabular}{lcc}
\hline Group & N & Mean \pm SD \\
\hline Er:YAG laser & 20 & $14.4 \pm 1.7$ \\
CO2 laser & 20 & $10.6 \pm 1.9$ \\
Control & 20 & $7.7 \pm 1.8$ \\
\hline
\end{tabular}

tensile or microtensile tests to eliminate non-uniform stresses at the interface. ${ }^{32,33}$ However, the shear test is most commonly used for this purpose. Each test has its own advantages and disadvantages, and no consensus has been reached on the most preferred test. ${ }^{34,35}$ Although tensile tests are commonly used, they can lead to unequal stress distribution. ${ }^{36}$ Moreover, sample preparation in this test is complex and if not properly controlled, torque stresses are created, decreasing the bond strength. ${ }^{37}$ On the other hand, very small samples are required for the microtensile test to equalize the stress distribution. The microtensile test is difficult to perform and is easily affected by different variables. Although the microshear test is easier than the microtensile test, its superiority to the conventional shear test has not been confirmed. ${ }^{37}$ The shear test is performed easily and is suitable for the prediction of the performance of materials. It can simulate the loads applied to materials in the oral environment. ${ }^{29,38,39}$ However, since the clinical setting is more complex, the results of in vitro studies should be interpreted with caution. ${ }^{37}$ Thus, the shear test was used in this study.

The efficacy of several surface treatments has been evaluated to overcome the challenges encountered in the bonding of composite resin veneers to PEEK. Laser irradiation is among the suggested surface treatments for this purpose. Researchers have recently focused on laser application to enhance the bonding of different dental materials such as ceramics and resin-based materials. ${ }^{15,17,28,31,40-43}$ The Er:YAG laser is the most commonly used laser type for the surface treatment of dental materials. ${ }^{29,31}$ Different energy levels of the Er:YAG laser have been used by investigators. ${ }^{44-46}$ In this study, we preferred to use lower powers of the Er:YAG laser because the use of higher laser powers (400 and $600 \mathrm{~mJ}$ ) would cause excessive destruction of material. ${ }^{47}$

The CO2 laser is also used in dentistry. Evidence shows that it is suitable for the surface treatment of ceramic materials, probably because of its wavelength, which is almost totally absorbed by the ceramic substrates. ${ }^{31}$ Akyil et al reported that the $\mathrm{CO} 2$ laser with $4 \mathrm{~W}$ output power can be used for the surface treatment of Y-TZP ceramics. ${ }^{43}$ Therefore, there is a possibility that this laser type can be used for PEEK surface treatment as well. Thus, the 4 W CO2 laser was used in this study. To the best of the authors' knowledge, no previous study has evaluated the effect of surface treatment with the $\mathrm{CO} 2$ laser on the bond strength of PEEK to composite resin veneers.

Several studies have evaluated the efficacy of laser 
irradiation in the surface treatment of ceramics, particularly zirconia. ${ }^{30,31,43}$ However, studies regarding the use of lasers for the surface treatment of PEEK to enhance its bond strength to composite resin veneers are limited. As a result, there have not been many studies to compare our results with the results of theirs. To the best of the authors' knowledge, only Ates et $\mathrm{al}^{29}$ have previously studied this topic. They used the Er:YAG laser for the surface treatment of PEEK. They evaluated the effect of laser irradiation alone and in combination with airborne particle abrasion and silica coating. They found that airborne particle abrasion and silica coating and their combination with the Er:YAG laser created a durable bond between PEEK and composite resin veneers. However, laser irradiation alone had no positive effect on the bond between the 2 materials. According to ISO 10477, the minimum acceptable SBS is $5 \mathrm{MPa}$ at the interface of resin-based materials and substrates. ${ }^{48}$ The minimum clinical SBS of resin-based materials in the oral environment has been reported to be 10 to 12 $\mathrm{MPa} .{ }^{49,50}$ In the study by Ates et al, ${ }^{29}$ although the SBS values were within the range suggested by ISO 10477, the SBS values obtained in the control and laser groups were lower than the clinically required values. In the present study, however, the SBS values in both Er:YAG $(14.5 \mathrm{MPa})$ and CO2 $(10.5 \mathrm{MPa})$ laser groups were higher than the minimally required threshold in the clinical setting (although the SBS value in the $\mathrm{CO} 2$ group was borderline).

In general, 2 main mechanisms in laser-induced surface modification has been suggested: photochemical and thermal. ${ }^{51}$ The factors affecting these phenomena are material features, laser wavelengths and intensities, and the operation mode of the laser. ${ }^{52,53}$ As CO2 and Er:YAG lasers operate at longer wavelengths and cannot break common molecular bonds in polymeric materials due to their insufficient photon energies, they may not be suitable for the modification of different polymers by photochemical mechanisms. Therefore, they possibly work in a thermal way. ${ }^{53}$ In a thermal mechanism, the material must absorb the radiation significantly to induce enough temperature increase allowing reactions to proceed. In other words, surface modifications occurred due to the thermal heating effect of the laser. Absorbed energy in a material prompts the atoms of this material to move within the lattice and collide with each other. Moreover, it increases the density of free electrons and offers a considerable amount of kinetic energy. ${ }^{53}$ In the present study, contrary to the Er-YAG laser, the results for the CO2 laser showed that the inertness of the PEEK surface was influenced only, to a minor degree, by the radiation, which is consistent with the study by Hartwig et al. ${ }^{24}$

One of the most important parameters in the surface modification is the laser wavelength because different amounts of energy are absorbed by the material at different wavelengths. Another parameter is power density which can be helpful when the material is not absorbing adequate amounts of energy at a specific wavelength. By increasing it, energy absorption by the material can be enhanced at that particular wavelength. ${ }^{53}$ Thus, further studies are required on different laser types and their ideal exposure parameters for this purpose.

Recently, a different pulse duration mode was introduced for the Er:YAG laser, namely the quantum square pulse (QSP) mode (LightWalker AT, Fotona, Ljubljana, Slovenia). ${ }^{29,54}$ In the QSP mode, a longer laser pulse is divided into several smaller pulses (pulse quanta), which follow each other in an optimally fast sequence. This enables the QSP mode to create low-energy short pulses with efficacy similar to that of laser pulses with higher energy and longer duration without compromising efficiency and accuracy. The main advantage of the QSP mode is that it minimizes the adverse effects of laser beam scattering and absorption in the particle mass during ablation ${ }^{54}$ Thus, although the Er:YAG laser has high penetration depth, the QSP mode may be more effective in creating an optimal substrate surface. With regard to the surface treatment of PEEK, only one study used the QSP mode and assessed the effect of the laser on the bonding of composite resin veneers to PEEK. ${ }^{29}$

Kurklu et al, ${ }^{55}$ in 2013, used graphite powder and hydroxyapatite for further energy absorption in the use of Nd:YAG, Er:YAG and CO2 lasers, which enabled the creation of a rough surface with lower laser powers. In the study by Kurklu et al, ${ }^{55} \mathrm{CO} 2, \mathrm{Nd}$ :YAG and Er:YAG lasers at different powers were shown to be effective in different restorative materials. Thus, if these particles are used on PEEK prior to laser irradiation, a higher SBS may be achieved; this topic needs to be investigated in future studies.

Not performing thermocycling or long-term water storage was among the limitations of this study. Surface roughness following the surface treatment with the laser was not evaluated in this study either, which needs to be evaluated in future studies. Moreover, only one type of composite resin veneer was used in this study, which decreases the generalizability of the results and its comparability with other studies.

This study had an in vitro design; therefore, the obtained results should be interpreted by taking into account the limitations of in vitro studies. Loads applied in vitro are different from those applied in the clinical setting. Thus, long-term clinical studies in the oral environment are required to assess the success of the bond of the veneering composites to PEEK surfaces.

\section{Conclusion}

Within the limitations of this study, it may be concluded that:

1. Surface treatment with Er:YAG and CO2 lasers yields the minimal clinically acceptable SBS values; 
the value obtained in the $\mathrm{CO} 2$ laser group was borderline.

2. The highest SBS values were noted in the Er:YAG laser group. Thus, Er:YAG laser irradiation can be a suitable method for increasing the SBS of composite resin veneers to the surface of PEEK coping. Further studies are required to find the most efficient type and parameters of a laser for this purpose.

\section{Ethical Considerations}

This research is an in-vitro study, so there are no ethical issues to be stated.

\section{Conflict of Interests}

The authors declared no potential conflicts of interest with respect to the research, authorship, and/or publication of this article.

\section{References}

1. Stawarczyk B, Eichberger M, Uhrenbacher J, Wimmer T, Edelhoff D, Schmidlin PR. Three-unit reinforced polyetheretherketone composite FDPs: influence of fabrication method on load-bearing capacity and failure types. Dent Mater J. 2015;34(1):7-12. doi: 10.4012/ dmj.2013-345.

2. Stawarczyk B, Beuer F, Wimmer T, Jahn D, Sener B, Roos $\mathrm{M}$, et al. Polyetheretherketone-a suitable material for fixed dental prostheses? J Biomed Mater Res B Appl Biomater. 2013;101(7):1209-16. doi: 10.1002/jbm.b.32932.

3. Najeeb S, Zafar MS, Khurshid Z, Siddiqui F. Applications of polyetheretherketone (PEEK) in the oral implantology and prosthodontics. J Prosthodont Res. 2016;60(1):12-9. doi: 10.1016/j.jpor.2015.10.001.

4. Fuhrmann G, Steiner M, Freitag-Wolf S, Kern M. Resin bonding to three types of polyaryletherketones (PAEKs) - Durability and influence of surface conditioning. Dent Mater. 2014;30(3):357-63. doi: 10.1016/j. dental.2013.12.008.

5. Zeighami S, Mirmohammadrezaei S, Safi M, Falahchai SM. The effect of core and veneering design on the optical properties of polyether ether ketone. Eur J Prosthodont Restor Dent. 2017;25(4):201-8. doi: 10.1922/ ejprd_01720zeighami08.

6. Stawarczyk B, Bähr N, Beuer F, Wimmer T, Eichberger $\mathrm{M}$, Gernet $\mathrm{W}$, et al. Influence of plasma pretreatment on shear bond strength of self-adhesive resin cements to polyetheretherketone. Clin Oral Investig. 2014;18(1):16370. doi: 10.1007/s00784-013-0966-7.

7. Kern M, Lehmann F. Influence of surface conditioning on bonding to polyetheretherketon (PEEK). Dent Mater. 2012;28(12):1280-3. doi: 10.1016/j.dental.2012.09.010.

8. Rosentritt M, Preis V, Behr M, Sereno N, Kolbeck C. Shear bond strength between veneering composite and PEEK after different surface modifications. Clin Oral Investig. 2015;19(3):739-44. doi: 10.1007/s00784-014-1294-2.

9. Stawarczyk B, Jordan P, Schmidlin PR, Roos M, Eichberger $\mathrm{M}$, Gernet W, et al. PEEK surface treatment effects on tensile bond strength to veneering resins. J Prosthet Dent. 2014;112(5):1278-88. doi: 10.1016/j.prosdent.2014.05.014.
10. Schmidlin PR, Stawarczyk B, Wieland M, Attin T, Hämmerle $\mathrm{CH}$, Fischer J. Effect of different surface pretreatments and luting materials on shear bond strength to PEEK. Dent Mater. 2010;26(6):553-9. doi: 10.1016/j. dental.2010.02.003.

11. Stawarczyk B, Keul C, Beuer F, Roos M, Schmidlin PR. Tensile bond strength of veneering resins to PEEK: impact of different adhesives. Dent Mater J. 2013;32(3):441-8. doi: 10.4012/dmj.2013-011.

12. Keul C, Liebermann A, Schmidlin PR, Roos M, Sener B, Stawarczyk B. Influence of PEEK surface modification on surface properties and bond strength to veneering resin composites. J Adhes Dent. 2014;16(4):383-92. doi: 10.3290/j.jad.a32570.

13. Hallmann L, Mehl A, Sereno N, Hämmerle CHF. The improvement of adhesive properties of PEEK through different pre-treatments. Appl Surf Sci. 2012;258(18):72138. doi: 10.1016/j.apsusc.2012.04.040.

14. Caglar I, Ates SM, Yesil Duymus Z. An in vitro evaluation of the effect of various adhesives and surface treatments on bond strength of resin cement to polyetheretherketone. J Prosthodont. 2019;28(1):e342-e349. doi: 10.1111/ jopr.12791.

15. Henriques B, Fabris D, Mesquita-Guimarães J, Sousa AC, Hammes N, Souza JCM, et al. Influence of laser structuring of PEEK, PEEK-GF30 and PEEK-CF30 surfaces on the shear bond strength to a resin cement. $J$ Mech Behav Biomed Mater. 2018;84:225-34. doi: 10.1016/j. jmbbm.2018.05.008.

16. Uhrenbacher J, Schmidlin PR, Keul C, Eichberger M, Roos $\mathrm{M}$, Gernet W, et al. The effect of surface modification on the retention strength of polyetheretherketone crowns adhesively bonded to dentin abutments. J Prosthet Dent. 2014;112(6):1489-97. doi: 10.1016/j.prosdent.2014.05.010.

17. Zhou L, Qian Y, Zhu Y, Liu H, Gan K, Guo J. The effect of different surface treatments on the bond strength of PEEK composite materials. Dent Mater. 2014;30(8):e209-e15. doi: 10.1016/j.dental.2014.03.011.

18. Silthampitag $\mathrm{P}$, Chaijareenont $\mathrm{P}$, Tattakorn K, Banjongprasert C, Takahashi H, Arksornnukit M. Effect of surface pretreatments on resin composite bonding to PEEK. Dent Mater J. 2016;35(4):668-74. doi: 10.4012/ dmj.2015-349.

19. Sproesser O, Schmidlin PR, Uhrenbacher J, Roos M, Gernet W, Stawarczyk B. Effect of sulfuric acid etching of polyetheretherketone on the shear bond strength to resin cements. J Adhes Dent. 2014;16(5):465-72. doi: 10.3290/j. jad.a32806.

20. Briem D, Strametz S, Schröder K, Meenen NM, Lehmann W, Linhart W, et al. Response of primary fibroblasts and osteoblasts to plasma treated polyetheretherketone (PEEK) surfaces. J Mater Sci Mater Med. 2005;16(7):671-7. doi: 10.1007/s10856-005-2539-z.

21. Foerch R, Izawa J, Spears G. A comparative study of the effects of remote nitrogen plasma, remote oxygen plasma, and corona discharge treatments on the surface properties of polyethylene. J Adhes Sci Technol. 1991;5(7):549-64. doi: $10.1163 / 156856191 X 00747$.

22. Wilson A, Jones I, Salamat-Zadeh F, Watts JF. Laser surface modification of poly (etheretherketone) to enhance surface free energy, wettability and adhesion. Int J Adhes 
Adhes. 2015;62:69-77. doi: 10.1016/j.ijadhadh.2015.06.005.

23. Tavakoli SM. Surface preparation: power beams clean up. Assembly Autom. 1994;14(4):36-8. doi: 10.1108/ EUM0000000004219.

24. Hartwig A, Hunnekuhl J, Vitr G, Dieckhoff S, Vohwinkel $\mathrm{F}$, Hennemann OD. Influence of $\mathrm{CO} 2$ laser radiation on the surface properties of poly (ether ether ketone). J Appl Polym Sci. 1997;64(6):1091-6. doi: 10.1002/(SICI)10974628(19970509)64:6<1091::AID-APP8>3.0.CO;2-G.

25. Zhang C, Zhang G, Ji V, Liao H, Costil S, Coddet C. Microstructure and mechanical properties of flame-sprayed PEEK coating remelted by laser process. Prog Org Coat. 2009;66(3):248-53. doi: 10.1016/j.porgcoat.2009.08.002.

26. Soveja A, Sallamand P, Liao H, Costil S. Improvement of flame spraying PEEK coating characteristics using lasers. J Mater Process Tech. 2011;211(1):12-23. doi: 10.1016/j. jmatprotec.2010.08.002

27. Garcia-Alonso D, Serres N, Demian C, Costil S, Langlade C, Coddet C. Pre-/during-/post-laser processes to enhance the adhesion and mechanical properties of thermalsprayed coatings with a reduced environmental impact. J Therm Spray Techn. 2011;20(4):719-35. doi: 10.1007/ s11666-011-9629-x.

28. Tsuka H, Morita K, Kato K, Kimura H, Abekura H, Hirata $\mathrm{I}$, et al. Effect of laser groove treatment on shear bond strength of resin-based luting agent to polyetheretherketone (PEEK). J Prosthodont Res. 2019;63(1):52-7. doi: 10.1016/j. jpor.2018.08.001.

29. Ates SM, Caglar I, Yesil Duymus Z. The effect of different surface pretreatments on the bond strength of veneering resin to polyetheretherketone. J Adhes Sci Technol. 2018;32(20):2220-31.doi: 10.1080/01694243.2018.1468534.

30. Akhavan Zanjani V, Ahmadi H, Nateghifard A, Ghasemi A, Torabzadeh H, Abdoh Tabrizi M, et al. Effect of different laser surface treatment on microshear bond strength between zirconia ceramic and resin cement. J Investig Clin Dent. 2015;6(4):294-300. doi: 10.1111/jicd.12105.

31. Akın H, Ozkurt Z, Kırmalı O, Kazazoglu E, Ozdemir AK. Shear bond strength of resin cement to zirconia ceramic after aluminum oxide sandblasting and various laser treatments. Photomed Laser Surg. 2011;29(12):797-802. doi: 10.1089/pho.2011.3039.

32. Aboushelib MN, Kleverlaan CJ, Feilzer AJ. Microtensile bond strength of different components of core veneered all-ceramic restorations. Part 3: double veneer technique. J Prosthodont. 2008;17(1):9-13. doi: 10.1111/j.1532849X.2007.00244.x.

33. Aboushelib MN, de Jager N, Kleverlaan CJ, Feilzer AJ. Microtensile bond strength of different components of core veneered all-ceramic restorations. Dent Mater. 2005;21(10):984-91. doi: 10.1016/j.dental.2005.03.013.

34. Della Bona A, van Noort R. Shear vs. tensile bond strength of resin composite bonded to ceramic. J Dent Res. 1995;74(9):1591-6. doi: 10.1177/00220345950740091401.

35. Braga RR, Meira JB, Boaro LC, Xavier TA. Adhesion to tooth structure: a critical review of "macro" test methods. Dent Mater. 2010;26(2):e38-e49. doi: 10.1016/j. dental.2009.11.150.

36. Shimada Y, Yamaguchi S, Tagami J. Micro-shear bond strength of dual-cured resin cement to glass ceramics. Dent Mater. 2002;18(5):380-8. doi: 10.1016/S0109-
5641(01)00054-9.

37. Ereifej N, Rodrigues FP, Silikas N, Watts DC. Experimental and FE shear-bonding strength at core/veneer interfaces in bilayered ceramics. Dent Mater. 2011;27(6):590-7. doi: 10.1016/j.dental.2011.03.001.

38. Watanabe I, Nakabayashi N. Measurement methods for adhesion to dentine: the current status in Japan. J Dent. 1994;22(2):67-72. doi: 10.1016/0300-5712(94)90001-9.

39. Cardoso PE, Braga RR, Carrilho MR. Evaluation of micro-tensile, shear and tensile tests determining the bond strength of three adhesive systems. Dent Mater. 1998;14(6):394-8. doi: 10.1016/s0300-5712(99)00012-3.

40. Shiu P, De Souza-Zaroni WC, Eduardo Cde P, Youssef MN. Effect of feldspathic ceramic surface treatments on bond strength to resin cement. Photomed Laser Surg. 2007;25(4):291-6. doi: 10.1089/pho.2007.2018.

41. Subaşı MG, İnan Ö. Evaluation of the topographical surface changes and roughness of zirconia after different surface treatments. Lasers Med Sci. 2012;27(4):735-42. doi: 10.1007/s10103-011-0965-3.

42. Spohr AM, Borges GA, Júnior LH, Mota EG, Oshima HM. Surface modification of In-Ceram Zirconia ceramic by Nd:YAG laser, Rocatec system, or aluminum oxide sandblasting and its bond strength to a resin cement. Photomed Laser Surg. 2008;26(3):203-8. doi: 10.1089/ pho.2007.2130

43. Akyil MS, Uzun IH, Bayindir F. Bond strength of resin cement to yttrium-stabilized tetragonal zirconia ceramic treated with air abrasion, silica coating, and laser irradiation. Photomed Laser Surg. 2010;28(6):801-8. doi: 10.1089/pho.2009.2697.

44. Korkmaz Y, OzelE, Attar N, Bicer CO, FiratliE. Microleakage and scanning electron microscopy evaluation of all-in-one self-etch adhesives and their respective nanocomposites prepared by erbium:yttrium-aluminum-garnet laser and bur. Lasers Med Sci. 2010;25(4):493-502. doi: 10.1007/ s10103-009-0672-5.

45. Chousterman M, Heysselaer D, Dridi S, Bayet F, Misset B, Lamard L, et al. Effect of acid etching duration on tensile bond strength of composite resin bonded to erbium:yttrium-aluminium-garnet laser-prepared dentine. Preliminary study. Lasers Med Sci. 2010;25(6):855-9. doi: 10.1007/s10103-009-0719-7.

46. de Oliveira Ortolan AS, Torres CP, Gomes-Silva JM, de Menezes-Oliveira MA, Pécora JD, Palma-Dibb RG, et al. Effect of erbium-doped yttrium aluminium garnet laser parameters on ablation capacity and morphology of primary dentin. Photomed Laser Surg. 2009;27(6):885-90. doi: 10.1089/pho.2008.2358.

47. Cavalcanti AN, Pilecki P, Foxton RM, Watson TF, Oliveira MT, Gianinni M, et al. Evaluation of the surface roughness and morphologic features of Y-TZP ceramics after different surface treatments. Photomed Laser Surg. 2009;27(3):473-9. doi: 10.1089/pho.2008.2293.

48. International Organization for Standardization. Dentistry polymer-based crown and bridge materials (ISO10477). Geneva: ISO; 2004.

49. Thurmond JW, Barkmeier WW, Wilwerding TM. Effect of porcelain surface treatments on bond strengths of composite resin bonded to porcelain. J Prosthet Dent. 1994;72(4):355-9. doi: 10.1016/0022-3913(94)90553-3. 
50. Piwowarczyk A, Lauer H, Sorensen JA. The shear bond strength between luting cements and zirconia ceramics after two pre-treatments. Oper Dent. 2005;30(3):382-8.

51. Srinivasan V, Smrtic MA, Babu SV. Excimer laser etching of polymers. J Appl Phys. 1986;59(11):3861-7. doi: $10.1063 / 1.336728$

52. Srinivasan R. Interaction of laser radiation with organic polymers. In: Laser Ablation. Berlin, Heidelberg: Springer; 1994. p. 107-133. doi: 10.1007/978-3-642-78720-1_5.

53. Ozdemir M, Sadikoglu H. A new and emerging technology: Laser-induced surface modification of polymers. Trends
Food Sci Tech. 1998;9(4):159-67. doi: 10.1016/S09242244(98)00035-1.

54. Lukac M, Primc NM, Pirnat S. Quantum square pulse Er:YAG lasers for fast and precise hard dental tissue preparation. Journal of Laser and Health Academy. 2012;2012(1):14-21.

55. Kurklu D, Yanikoglu N. SEM evaluation of surface morphologic analysis of restorative materials with three laser treatment. J Dent Lasers. 2013;7(1):9-16. doi: 10.4103/0976-2868.118414 